\title{
Semantic memory and frontal executive function during transient global amnesia
}

\author{
J R Hodges
}

\begin{abstract}
To assess semantic memory and frontal executive function, two patients underwent neuropsychological testing during transient global amnesia (TGA) and after an interval of 6-8 weeks. In spite of a profound deficit in anterograde verbal and non-verbal memory, semantic memory was normal, as judged by category fluency measures, picture naming, and picture-word and picture-picture matching, and reading ability was normal. Similarly, there were no deficits on a number of tests known to be sensitive to frontal executive dysfunction. A hexamethyl-propylene-amine-oxime (HMPAO) single photon emission CT (SPECT) scan, obtained on one patient 24 hours post-TGA, showed focal left temporal lobe hypoperfusion which had resolved three months later. The observed dissociation between episodic and semantic memory is discussed in the light of contemporary cognitive theories of memory organisation.
\end{abstract}

(F Neurol Neurosurg Psychiatry 1994;57:605-608)

The term "transient global amnesia" (TGA) was first coined by Fisher and Adams" to describe a clinical syndrome characterised by the abrupt onset of severe anterograde amnesia, usually accompanied by repetitive questioning occurring in the middle aged or elderly, and lasting a few hours. During the attack patients remain alert and communicative, and personal identity is preserved. More recently, research criteria for the diagnosis have been proposed which include the following $^{2}$ : the attacks must be witnessed and information available from a capable observer who was present for most of the attack; there must be clear-cut anterograde amnesia during the attack; clouding of consciousness and loss of personal identity should be absent; there should be no accompanying focal neurological symptoms or signs; epileptic features must be absent; the attack must resolve within 24 hours; and patients with recent head injury or known active epilepsy are excluded.

Although several hundred patients who fulfil these criteria have been reported, ${ }^{2}$ there are still relatively few reports of neuropsychological testing during TGA. ${ }^{3-9}$ These studies have established that the pattern of memory impairment closely resembles that seen in patients with permanent amnesia, that is, there is preserved immediate or short-term memory (eg, digit span), but longer-term anterograde memory for verbal and non-verbal material is profoundly impaired. It is also apparent that most patients have a retrograde amnesia, although the extent of the deficit varies from fairly slight (ie, weeks or months) to very extensive (ie, many decades). However, a number of issues remain unsettled. In particular, the status of semantic memory and frontal "executive" function during TGA has been investigated very little. ${ }^{210}$

'Semantic memory' is the term applied to the component of long-term memory responsible for the storage and integrity of knowledge about the world, including the meaning of words and objects. ${ }^{11}{ }^{12}$ It is of considerable theoretical interest to know whether semantic memory is intact in TGA. First, it has been suggested that episodic (ie, memory for temporally specific events or episodes) and semantic memory are functionally separate systems which may dissociate; the degree of episodic memory impairment in TGA is clearly profound and it is therefore of interest to know whether semantic memory is impaired during TGA. Second, the temporal neocortex, especially on the left side, appears to be the area most critical for the maintenance of semantic memory. ${ }^{12}$ Cerebral perfusion studies using single photon emission CT (SPECT) have usually shown bilateral temporal lobe hypoperfusion extending beyond the structures involved in episodic memory (the hippocampal complex) during TGA.9 101314 Thus, it is possible that semantic memory may be impaired in patients with TGA, but the deficit has been overshadowed by profound changes in episodic memory.

The status of frontal "executive" function during TGA is also of interest. Patients with permanent amnesia secondary to diencephalic damage invariably have additional executive deficits, presumably secondary to functional frontal deactivation. ${ }^{15}$ By contrast, in hippocampal amnesia executive function is unimpaired. As functional imaging studies by SPECT have usually shown pathological changes confined to the temporal regions, frontal executive function should also be normal during TGA. On the other hand, Goldenberg ${ }^{10}$ has recently argued, on the basis of a review of the literature, that there may well be a diffuse impairment in cognitive function, including frontal executive abilities during TGA.

The aim of the present study was to investigate semantic memory and executive function 
Table 1 Basic demographic and clinical details of the two patients

\begin{tabular}{lll}
\hline & Patient 1 & Patient 2 \\
\hline $\begin{array}{l}\text { Age (years)/Sex } \\
\text { Prior TGA }\end{array}$ & $69 / \mathrm{M}$ & $62 / \mathrm{M}$ \\
$\begin{array}{l}\text { Cerebrovascular risk } \\
\text { factors }\end{array}$ & No & No \\
$\begin{array}{l}\text { Migraine } \\
\text { Length of TGA (hours) }\end{array}$ & Absent & Absent \\
$\begin{array}{l}\text { Repetitive questioning } \\
\text { Length of retrograde } \\
\text { amnesia }\end{array}$ & Yes & Yes \\
$\begin{array}{l}\text { Fulfil research criteria } \\
\text { for TGA }\end{array}$ & Months & 8 \\
$\begin{array}{l}\text { CT scan } \\
\text { EEG post attack }\end{array}$ & Yes & Months \\
SPECT & Normal & Yes \\
& Normal & Normal \\
\hline Left temporal & Normal \\
\hline As judged by informal performed
\end{tabular}

^As judged by informal assessment.

in TGA. Two patients were tested during the acute attack, and again after an interval of 6-8 weeks. As the features of the attack were virtually identical - and characteristic of TGAin both patients, only patient 1 will be described in detail. Basic demographic and clinical details of the two cases are summarised in table 1 . Patient 1 also underwent SPECT scanning 24 hours after the attack and again after three months.

\section{Case report}

Patient 1, a 69-year-old man, presented on 14 February 1993 in the midst of his first attack of TGA. At approximately 11:00 he became acutely amnesic immediately after sexual intercourse with his wife. He exhibited the typical features of repetitive questioning and was disoriented in time. He rapidly forgot any new material and it was clear that he had a dense retrograde amnesia extending back for at least a week-he had forgotten an impor-

Table 2 Results of neuropsychological testing during TGA and after an interval of 6-8 weeks

\begin{tabular}{|c|c|c|c|c|c|c|}
\hline & \multicolumn{2}{|c|}{ Patient 1} & \multicolumn{2}{|c|}{ Patient 2} & \multicolumn{2}{|c|}{ Controls $\star$} \\
\hline & During & After & During & After & Mean & $S D$ \\
\hline \multicolumn{7}{|l|}{ Digit span } \\
\hline Forwards & 7 & 7 & 7 & 7 & $6 \cdot 8$ & $1 \cdot 0$ \\
\hline Backwards & 3 & 4 & 4 & 4 & $4 \cdot 7$ & $1 \cdot 2$ \\
\hline \multicolumn{7}{|l|}{ Logical memory† } \\
\hline Immediate $(2 \mathrm{i})$ & $2 \cdot 5$ & $7 \cdot 0$ & $3 \cdot 0$ & $11 \cdot 0$ & $11 \cdot 4$ & $4 \cdot 0$ \\
\hline Delayed & 0 & $3 \cdot 0$ & 0 & $7 \cdot 0$ & $8 \cdot 3$ & $3 \cdot 4$ \\
\hline \multicolumn{7}{|l|}{ Rey figure (36) } \\
\hline Copy & 30 & 32 & 34 & 35 & $34 \cdot 1$ & $2 \cdot 9$ \\
\hline Recall & 0 & 10 & 0 & 15 & $15 \cdot 4$ & $7 \cdot 3$ \\
\hline \multicolumn{7}{|l|}{ Fluency } \\
\hline Living & 71 & 76 & 68 & 70 & $57 \cdot 4$ & $12 \cdot 7$ \\
\hline Artefactual & 58 & 64 & 65 & 62 & $55 \cdot 2$ & $8 \cdot 5$ \\
\hline Perseverations (\%) & 10 & 0 & 12 & 0 & - & - \\
\hline Naming (48) & 48 & 48 & 46 & 47 & $43 \cdot 5$ & $2 \cdot 3$ \\
\hline Picture-pointing (48) & 48 & 48 & 47 & 48 & $47 \cdot 3$ & $1 \cdot 0$ \\
\hline \multicolumn{7}{|l|}{ Pyramids and } \\
\hline palm trees (52) & 52 & NA & 52 & NA & $51 \cdot 0$ & $1 \cdot 5$ \\
\hline Raven's APM (12) & 6 & 7 & 7 & 7 & & \\
\hline \multicolumn{7}{|l|}{ Trails } \\
\hline$A(s)$ & 41 & 62 & 50 & 45 & & \\
\hline B (s) & 82 & 109 & 95 & 90 & & \\
\hline \multicolumn{7}{|l|}{ Stroop test } \\
\hline I (s) & 100 & 97 & 115 & 125 & & \\
\hline II (s) & 250 & 218 & 190 & 210 & & \\
\hline Errors & 0 & 0 & 1 & 0 & & \\
\hline
\end{tabular}

*Control data based on 25 age matched normal controls.

tFrom Wechsler memory scale-Revised. ${ }^{16}$

†Condition I reading colour names but ignoring colour. Condition II naming colours but ignoring colour names.

ing colour names. tant dinner which had occurred a few days before. He complained of no other neurological symptoms. In the past he has suffered from benign coital cephalgia, but was generally fit and well. After assessment by his general practitioner, he was referred to Addenbrooke's Hospital. General medical and neurological examination were normal. Neuropsychological assessment began at 18:00. At that time he was still clearly amnesic with virtually no retention of new information, such as a name and address. His retrograde amnesia, assessed informally with collaborative evidence from his wife, indicated a dense remote memory deficit of weeks with a patchy impairment extending over a period of months. By 21:00 the retrograde amnesia had shrunk to about 24 hours and he was beginning to retain new information. Testing was discontinued at that stage. After the attack he was left with an amnesic gap of 12 hours which encompassed the duration of the amnesic episode, plus two hours preceding it during which time his behaviour was normal.

The following day he underwent a CT scan, EEG, chest radiograph, and ECG, all of which were normal. A hexamethyl-propyleneamine-oxime (HMPAO) SPECT scan, performed on the day after the attack, showed an area of focally reduced perfusion in the left temporal lobe, involving predominantly the medial temporal area. Repeat examination three months later was normal.

\section{NEUROPSYCHOLOGICAL ASSESSMENT}

Both patients underwent testing during TGA and after an interval of 6-8 weeks; the results are shown in table 2. Anterograde episodic memory for verbal material, as judged by performance on the logical memory (story recall) part of the Wechsler memory scale-revised ${ }^{16}$ was profoundly impaired in both patients. Similarly, neither patient retained any elements of the Rey complex figure after a delay of approximately 30 minutes, despite normal copying of the figure. When re-tested both had improved very considerably. The first patient's verbal memory was perhaps still slightly below that expected for his age and education. Patient 2 was considered to be entirely normal.

In contrast to their longer-term memory, immediate (short-term) memory, as judged by digit span, was normal in both patients and showed no change between the two test sessions.

Semantic memory was evaluated using components of a battery which has been described in detail elsewhere. ${ }^{17}$ In brief, the battery employs a consistent set of stimulus items designed to assess input to, and output from, central representational knowledge about the sáme group of items via different sensory modalities. It contains 48 items chosen to represent three categories of animals (land animals, sea creatures, and birds) and three categories of artefactual items (household items, vehicles, and musical instruments), matched for word frequency. The following sub-tests from the battery were 
administered: category fluency for each of the main semantic categories in the battery, naming of all 48 line drawings, picture-pointing in response to the spoken name (each array consisting of eight items from the same semantic category, such as birds). On each sub-test, both patients performed normally during TGA as judged against 25 normal controls roughly matched for age and IQ. On category fluency both patients produced an adequate total number of exemplars, although, in keeping with the severe amnesic state, approximately $10 \%$ of the responses were perseverations. On reassessment, the total number of responses was almost identical, but now without perseverative errors.

In addition, a picture-picture matching test designed to assess non-verbal semantic knowledge ${ }^{18}$ was administered. In this test, subjects are asked to match conceptually related pictures. For instance, the target picture of an Egyptian pyramid is presented above two drawings depicting a palm tree and a fir tree, and the subject is asked to say which one goes with the pyramid. Both patients performed flawlessly on this test during TGA and were, therefore, not reassessed.

The ability to read aloud words with an exceptional or irregular spelling-to-sound correspondence (eg, PINT, ISLAND, CELLIST) has been shown to depend upon intact semantic memory ${ }^{19}$; patients with semantic memory impairment exhibit the features of surface dyslexia, that is, defective irregular word reading with predominant regularisation errors (PINT to rhyme with MINT). To assess reading, the two patients were given the surface reading list devised by Patterson and Hodges, ${ }^{19}$ consisting of 252 words divided equally into regular and exception words from a range of frequencies (high, medium, and low). Both patients performed normally during TGA producing six and eight errors, respectively, all on low frequency irregular words. There was no significant change in their reading accuracy when re-tested 6-8 weeks later.

Frontal executive abilities were assessed by means of Raven's advanced progressive matrices (APM) ${ }^{20}$ the trail matching test (parts $A+B)^{21}$ and the Stroop test. ${ }^{22}$ Both patients performed normally during TGA, as judged against normative data for these tasks. There was some variability between the two test sessions, with slight decline on the Stroop test in patient 1 , and on the trail matching test in patient 2 . These relatively minor fluctuations can be considered within normal limits.

\section{Discussion}

The principal findings of normal semantic memory and frontal executive function during TGA confirm previous observations, which have suggested that TGA produces an unusually profound, yet pure, amnesic syndrome. ${ }^{2}$

The distinction between episodic and semantic memory was first fully developed by Tulving. ${ }^{11}$ Since then, it has been repeatedly suggested that the amnesic syndrome repre- sents a dissociation between grossly impaired episodic memory and normal semantic memory. ${ }^{15}$ The present study illustrates this dissociation very dramatically; both patients were unable to form new episodic traces, but exhibited normal levels of performance on a range of tasks designed to test semantic memory, including category fluency, picture naming, picture-word, and picture-picture matching. In keeping with these findings, there was no impairment in the patients' ability to read words with irregular spelling-to-sound correspondence. It has been shown that semantic memory breakdown leads to a selective deficit in irregular word reading with a pattern of surface dyslexia. ${ }^{23}$ Semantic memory has not been formally explored in TGA. One previous study documented preserved naming ability ${ }^{7}$ but another found mildly impaired naming compared to the same patients' performance after TGA. ${ }^{8}$

It could, however, be argued that the observed dissociation was not really one of episodic and semantic memory, but merely reflected a gross difference between the ability to lay down new memories and to retrieve older ones. Semantic memory, at least of the type assessed in this study, is generally acquired early in life and is reinforced by recurrent re-exposure. To establish a true dissociation between episodic and semantic memory, it would be necessary to demonstrate that patients could retrieve semantic information from the same life periods from which they were unable to retrieve episodic memories. In a recent study, Evans et al ${ }^{9}$ provided hints that this might indeed be the case; they showed that, during TGA, their patient performed normally on the semantic components of the autobiographical memory interview, ${ }^{24}$ but was impaired on the personal episodic part of the same schedule. A full discussion on the nature of episodic and semantic memory, and whether they are truly separate subsystems, is beyond the scope of this study. Many investigators now regard episodic and semantic memory as a continuum; all new information is probably acquired episodically, but by repeated exposure some facts become part of our semantic store. ${ }^{15}$ Certainly different brain structures appear critical for the acquisition of new material, and the storage of older, semantic-type memories. In TGA the former is profoundly disrupted, but the latter appears to be spared.

As predicted, frontal executive function was also normal during TGA. The patients' ability to perform difficult tasks such as the progressive matrices, ${ }^{20}$ trail matching (part B), ${ }^{21}$ and Stroop test ${ }^{22}$ was quite striking in view of their profound amnesia. Verbal fluency also depends upon intact initiation and is vulnerable to frontal and frontostriatal pathology. The patients' excellent performance on this task is further testimony to their intact executive function.

Cerebral perfusion studies in TGA have, on the whole, shown hypoperfusion confined to the temporal lobes, ${ }^{913} 14$ although in one study changes were most marked in the thala- 
mic region..$^{25}$ In the present study, a SPECT scan obtained 24 hours post-TGA showed focally reduced perfusion confined to the left temporal lobe, involving predominantly medial temporal structures. It is probable that the deficit was resolving and that during TGA bilateral changes would have been present. The most parsimonious interpretation of these reports is that the site of pathology in TGA varies; most commonly, the medial temporal region is involved, but occasionally the midline thalamic structures may bear the brunt.

This could explain the variable duration of retrograde amnesia during TGA. Hodges and Ward ${ }^{7}$ clearly demonstrated that, although all patients have a profound anterograde amnesia, the degree of retrograde memory impairment is extremely variable. It has recently been suggested, by Squire, ${ }^{23}$ that pathology limited to the hippocampus results in a pure anterograde amnesia, and only when other structures are also involved is there an accompanying retrograde amnesia.

1 Fisher CM, Adams RB. Transient global amnesia. Acta Neurol Scand 1964;40:1-83.

2 Hodges JR. Transient global amnesia: clinical and neuropsychological aspects. London: WB Saunders, 1991.

3 Caffarra P, Moretti G, Mazzucchi A, Parma M Neuropsychological testing during a transient global amnesia episode and its follow-up. Acta Neurol Scand 1981;63:44-50.

4 Regard $M$, Landis $T$. Transient global amnesia Neuropsychological dysfunction during attack and recovery in two "pure" cases. $\mathcal{f}$ Neurol Neurosurg Psychiatry 1984;47:668-72.

5 Lurusso GR, Stracciari A. Neuropsychological findings during a transient global amnesia attack and its follow up. Ital ₹ Neurol Sci 1986;7:45-9.

6 Kritchevsky M, Squire LR, Zouzounis JA. Transient global amnesia: characterisation of anterograde and retrograde amnesia. Neurology 1988;38:213-9.
7 Hodges JR, Ward CD. Observations during transient global amnesia: A behavioural and neuropsychological study of five cases. Brain 1989;112:595-620.

8 Kritchevsky M, Squire LR. Transient global amnesia: evidence for extensive, temporally graded retrograde amnesia. Neurology 1989;39:213-8.

9 Evans J, Wilson B, Wraight EP, Hodges JR. Neuropsychological and SPECT scan findings during and after transient global ame differential Neurosurg Psychiatry 1994;57:1227-30.

10 Goldenberg G. Transient global amnesia. In Baddeley A, Wilson B, Watts F (Eds), Handbook of memory disorder Chichester: John Wiley, (in press).

11 Tulving E. Elements of episodic memory. Oxford: Oxford University Press, 1983.

12 Hodges JR, Patterson K, Oxbury S, Funnell E. Semantic dementia: progressive fluent aphasia with temporal lobe atrophy. Brain 1992;155:1783-806.

13 Stillhard G, Landis T, Schiess R, Regard M, Sialer G. Bitemporal hypoperfusion in transient global amnesia: a $99 \mathrm{~m}-\mathrm{Tc}-\mathrm{HM}-\mathrm{PAO}$ SPECT and neuropsychological findings during and after an attack. $f$ Neurol Neurosur Psychiatry 1990;53:339-42.

14 Tanabe $\mathrm{H}$, Hashikawa TH, Nakagawa $\mathrm{K}$, et al. Memory loss due to transient hypoperfusion in the medial temporal lobes including the hippocampus. Acta Neurol Scand 1991;84:22-7.

15 Butters N, Stuss DT. Diencephalic amnesia In: Boller F, Grafman J (Eds), Handbook of neuropsychology, Vol 3.

16 Wechsler D. Wechsler memory scales-revised. New York: The Psychological Corporation, 1984

17 Hodges JR, Salmon DP, Butters N. Semantic memory mpairment in Alzheimer's disease: failure of access or degraded knowledge? Neuropsychologia 1992;30:301-14.

18 Howard D, Patterson K. Pyramids and palm trees: $A$ test of semantic access from pictures and words. Bury St Edmunds, Suffolk: Thames Valley Publishing, 1992.

19 Patterson K, Hodges JR. Loss of word meaning: implication for word reading. Neuropsychologia 1992;30 1025-40.

20 Raven JC. Advanced progressive matrices set 1. London: HK Lewis, 1958.

21 Reitan RM. Trail matching test. Manual for administration and scoring. Tucson, AZ: Reitan Neuropsychological and scoring. Tucson

22 Dodrill CB. The Stroop test. Seattle, Washington: Dodrill 1983

23 Squire LR. Memory and the hippocampus: a synthesis from findings with rats, monkeys and humans. Psychol Rev 1992;99:195-231.

24 Kopelman M, Wilson BA, Baddeley AD. The Autobiographical Memory Interview: A new assessment of autobiographical and personal semantic memory in amnesic patients. F Clin Exp Neuropsychol 1989;11 724-44.

25 Goldenberg G, Podreka I, Pfafflmeyer N, Wessely P, Deecke $\mathrm{L}$. Thalamic ischemia in transient global amnesia: a SPECT study. Neurology 1991;41:1748-52. 